\title{
A CONTRIBUIÇÃo DO DESIGN PARA A VALORIZAÇÃO DE PEQUENOS GRUPOS PRODUTIVOS
}

\author{
Julio Monteiro Teixiera \\ Universidade Federal de Santa Catarina \\ juliomontex@gmail.com \\ Giovanni Piazza \\ Universidade Federal de Santa Catarina \\ gio.piazza@gmail.com \\ Eugenio Andrés Díaz Merino \\ Universidade Federal de Santa Catarina \\ eugenio.merino@ufsc.br \\ Giselle Schmidt Alves Díaz Merino \\ Universidade Federal de Santa Catarina \\ gisellemerino@gmail.com \\ Robson Willian Fernandes \\ Universidade Federal de Santa Catarina \\ robsonwf@hotmail.com
}

\section{Resumo}

Esse artigo tem como objetivo identificar a contribuição do design para a valorização de pequenos grupos produtivos, por meio da identificação e proteção. Foi utilizado como metodologia projetual o Guia de Orientação para o Desenvolvimento de Projetos - GODP. Foram desenvolvidos sistemas de identidade visuais, incluindo aplicações como folders, estampas e aplicações em papelaria. O final concluiu-se que, a partir da atividade de extensão é possível criar um ambiente de aprendizado com projetos reais que, além de aproximar a academia da sociedade, permite desenvolver, testar e compartilhar ideias e experiências. Dessa forma, a valorização de pequenos grupos produtivos, ocorreu por meio de projetos gráficos que tinham por finalidade a identificação e proteção de organizações.

Palavras-chave: Design Social. Identificação. Proteção. Metodologia. 


\title{
THE DESIGN CONTRIBUTION FOR ENHANCE OF SMALLER PRODUCTIVE GROUPS
}

\begin{abstract}
This paper aims to identify the contribution of design to the enhance of smaller productive groups through the identification and protection. Projective methodology was used as the Guia de Orientação para o Desenvolvimento de Projetos - GODP. We developed visual identity systems, including applications such as folders, prints and stationery applications. The finale concluded that, from the extension activity is possible to create a learning environment with real projects that, in addition to bringing the academy society, allowed to develop, test and share ideas and experiences. Thus, the enhancement of smaller productive groups, occurred through graphic designs that were intended to identify and protect organizations
\end{abstract}

Keywords: Social Design. Identification. Protection. Methodology. 


\section{INTRODUÇÃO}

Esta pesquisa pertence ao projeto de extensão "Valorização e proteção da produção de pequenos produtores: cooperativas em Santa Catarina”. O projeto surgiu a partir da necessidade em compreender e atuar na realidade de pequenos grupos produtivos, quanto à produção, comercialização e principalmente a proposta de uma forma eficiente e eficaz de identificação e proteção.

No cenário mercadológico atual, às organizações se veem obrigadas a repensarem suas estratégias, bem como atuarem de maneira dinâmica, rápida e inovadora. Diante disso, meios de diferenciação e otimização no funcionamento das organizações e grupos produtivos, bem como a utilização de mecanismos de proteção legal, têm recebido destaque e ampliado o potencial das organizações no mercado, colaborando com a concorrência a nível global e também assegurando sua competitividade e permanência no mercado (TEIXEIRA, 2011).

As atividades realizadas neste trabalho buscaram, principalmente, atender demandas de design das organizações de forma que atuasse além do desenvolvimento de material gráfico visual. Possibilitando assim uma maior visibilidade à organização a partir da construção de uma identidade própria e diferenciada, agregando valor e diferenciando os grupos envolvidos. Tal preocupação com a valorização de grupos de pequeno porte pode ser identificada em outros esforços de pesquisa e extensão do mesmo grupo do qual este trabalho pertence, vale citar Merino (2010) e (2011), Teixeira (2011) e Andrade (2012).

Portanto, esse artigo tem como objetivo identificar a contribuição do design para a valorização de pequenos grupos produtivos, por meio da identificação e proteção. Para o desenvolvimento, foi utilizado como metodologia o Guia de Orientação para o Desenvolvimento de Projetos - GODP. A seguir são explicitados os processos metodológicos utilizados, bem como a sua aplicação em cada organização ou grupo produtivo.

\section{MATERIAL E MÉTODOS}

Como já fora dito anteriormente o GODP foi utilizado como metodologia. Esse guia possui três fases, são elas: inspiração, ideação e implementação e dividi-se em oito etapas (MERINO, 2011). 


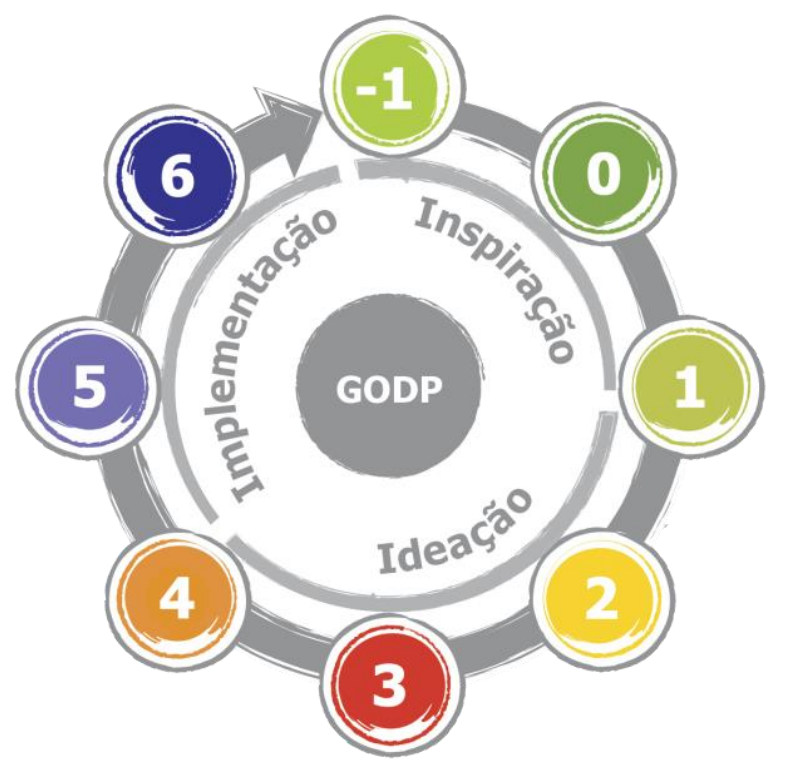

Figura 1 - Guia de Orientação para o Desenvolvimento de Produtos. Fonte: Merino, 2011.

Esta metodologia se apoia na proposta do Design Thinking (BROWN, WYATT, 2010) que apresentam três momentos no processo de desenvolvimento, sendo eles: Inspiração (etapas -1 / 0 / 1), Ideação (etapas 2 / 3 / 4) e Implementação (etapas 5 / 6) corroborado por (ROWE, 1987; BROWN, 2009; AMBROSE e HARRIS, 2010; DMI, 2010). A seguir são detalhadas segundo Merino (2011), cada uma das etapas:

\section{Etapa (-1) OPORTUNIDADES}

Nesta etapa serão verificadas as oportunidades do mercado/setores, conforme o produto a ser avaliado, considerando um panorama nacional e internacional e a atuação naeconomia. Desta forma, serão evidenciadas as necessidades de crescimento do setor e outras necessidades conforme o produto avaliado.

\section{Etapa (0) PROSPECÇÃO/SOLICITAÇÃO}

Nesta etapa, após a verificação das oportunidades é definida a demanda/problemática central que norteara o projeto.

\section{Etapa (1) LEVANTAMENTO DE DADOS}

Nesta etapa serão desenvolvidas as definições do projeto com base em um levantamento de dados em conformidade com as necessidades e expectativas do usuário, que contemplam os quesitos de usabilidade, ergonomia e antropometria, assim como com as 
UNIVERSIDADE FEDERAL DE SANTA CATARINA

PRÓ-REITORIA DE CULTURA E EXTENSÃO

DEPARTAMENTO DE PROJETOS DE EXTENSÃO

EXTENSIO - REVISTA ELETRÔNICA DE EXTENSÃO

conformidades da legislação que trata das normas técnicas para o desenvolvimento dos produtos.

\section{Etapa (2) ORGANIZAÇÃO E ANÁLISE DOS DADOS}

Após o levantamento das informações, na forma de dados, os mesmos são organizados e analisados. Neste momento podem ser utilizadas técnicas analíticas que permitirão definir as estratégias de projeto.

\section{Etapa (3) ETAPA DE CRIAÇÃO}

De posse das estratégias de projeto, são definidos os conceitos globais do projeto, sendo geradas as alternativas preliminares. Estas são submetidas a uma nova análise se utilizando de técnicas e ferramentas, permitindo a escolha daquelas que respondem de melhor forma as especificações de projeto e atendimento dos objetivos.

\section{Etapa (4) ETAPA EXECUTIVA}

Nesta etapa, considera-se o ciclo de vida do produto em relação às propostas. A partir das propostas são desenvolvidos protótipos (escala) e modelados matematicamente, para posteriormente, após as analises elaborar o(s) protótipo(s) funcional do(s) escolhido(s), para os testes de usabilidade.

\section{Etapa (5) COMERCIALIZAÇÃO}

Nesta etapa, já sendo definida a proposta que atende as especificações, o produto é testado em situação real, junto a usuários. Somado a este são realizadas pesquisa de ponto de venda, e junto a potenciais consumidores. Os produtos sejam no seu lote piloto, ou ainda em protótipos funcionais serão expostos em pontos de venda, para avaliar o seu desempenho. Neste item utilizam-se ferramentas de avaliação de ergonomia, usabilidade e qualidade aparente.

\section{Etapa (6) USO, REUSO E DESCARTE}

Esta etapa considera, que todo projeto deve considerar os aspectos de sustentabilidade, focado no destino dos produtos após o termino do tempo de vida útil. Por esta razão é considerada de vital importância, no sentido que poderá gerar novas oportunidades de projeto.

\section{Aplicação do Método}

A aplicação da metodologia GODP, como mencionado anteriormente, se deu pela realização de atividades projetuais com diferentes grupos produtivos de pequeno porte. 


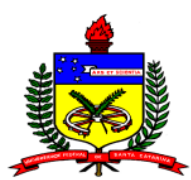

UNIVERSIDADE FEDERAL DE SANTA CATARINA

PRÓ-REITORIA DE CULTURA E EXTENSÃO

DEPARTAMENTO DE PROJETOS DE EXTENSÃO

EXTENSIO - REVISTA ELETRÔNICA DE EXTENSÃO

Estes projetos foram realizados entre os períodos de Maio de 2011 a Março de 2012, conforme demonstrado em ordem cronológica na Ilustração 02

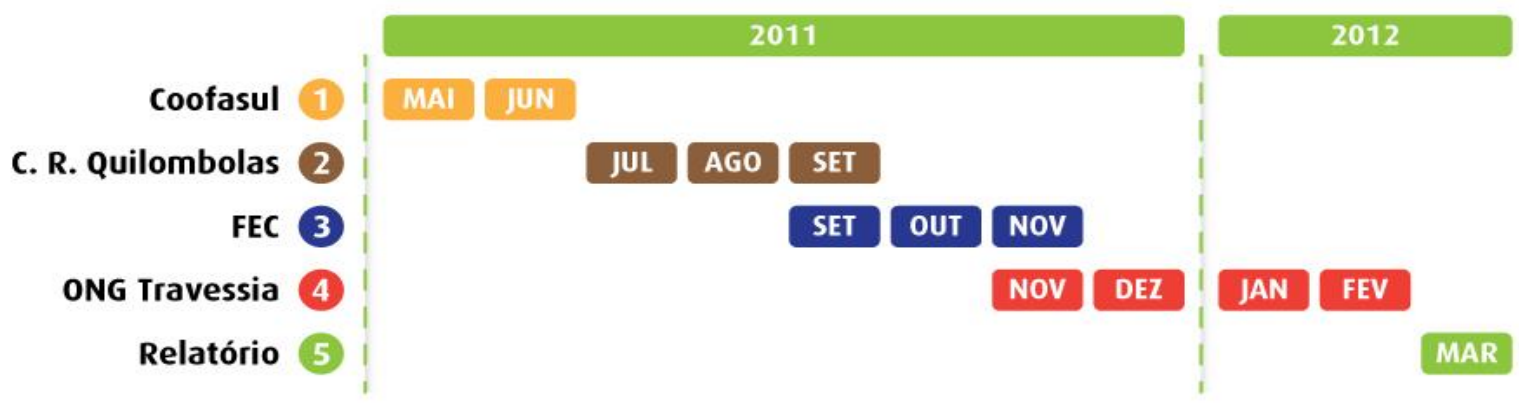

Figura 2 - Linha do Tempo de Atividades Projetuais. Fonte: Acervo NGD, 2012.

Como podemos observar, o número de organizações envolvidas nas atividades projetuais foi alto e, consequentemente, os projetos geraram impacto positivo em uma ampla gama de pessoas de diferentes regiões de Santa Catarina, conforme demonstra a Ilustração 3.

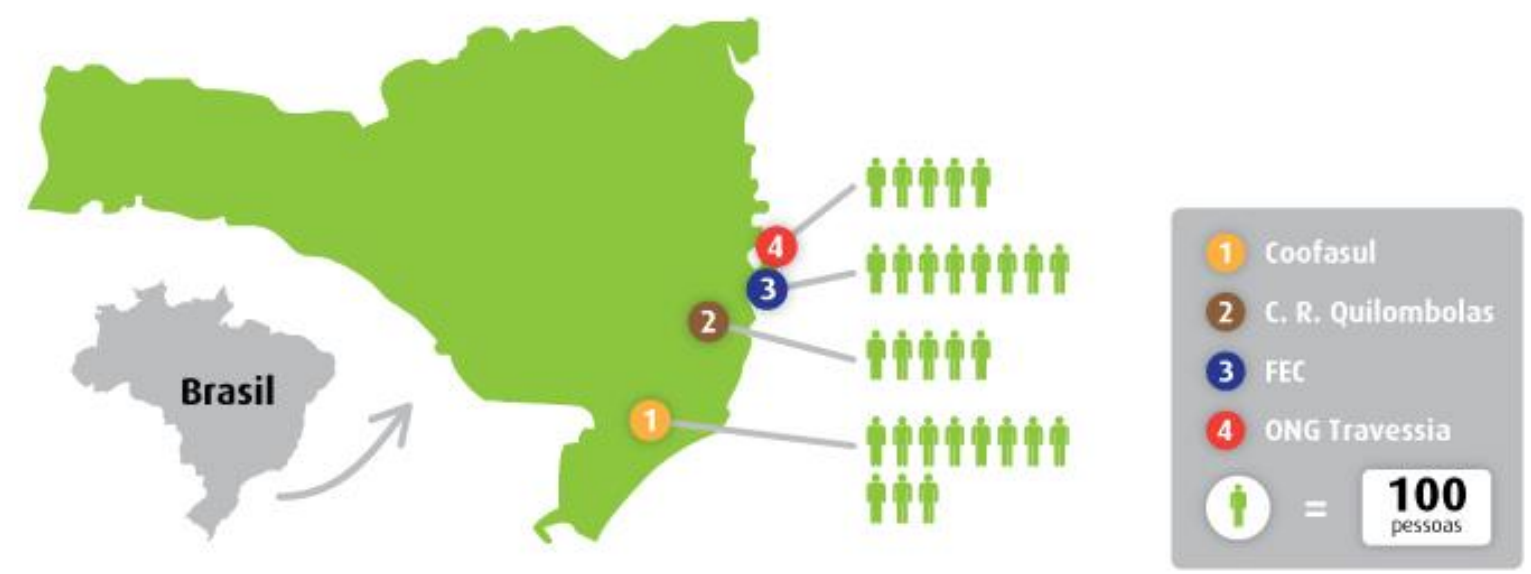

Figura 3 - Pessoas atingidas pelas atividades projetuais. Fonte: Acervo NGD, 2012.

\section{Coofasul}

As primeiras atividades realizadas no período de maio a junho de 2011 que consistia no fechamento de arquivo das embalagens de mel, suco de uva, cachaça, vinho branco e vinho tinto desenvolvidas para a Coofasul (Cooperativa Familiar Agroindustrial Sul-Catarinense), que apresenta, atualmente, 31 associados e conta com o apoio e a orientação da EPAGRI na 


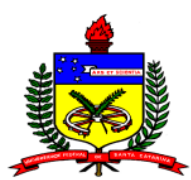

UNIVERSIDADE FEDERAL DE SANTA CATARINA

PRÓ-REITORIA DE CULTURA E EXTENSÃO

DEPARTAMENTO DE PROJETOS DE EXTENSÃO

EXTENSIO - REVISTA ELETRÔNICA DE EXTENSÃO

parte técnica. Foi realizado um estudo no acervo do núcleo sobre as pesquisas já realizadas, verificando que trabalhos foram realizados e qual foi à interação entre o NGD e Coofasul. Foi também analisado o material gráfico desenvolvido para cooperativa. Tendo como base o conhecimento adquirido por meio do estudo do material encontrado, pôde-se então partir para parte de análise das embalagens. Nesta etapa obteve-se foi realizado um estudo referente à legislação aplicada no desenvolvimento de embalagens.

\section{Comunidade Remanescentes Quilombolas}

A Comunidade de Remanescentes Quilombolas de Santa Cruz localizada em Paulo Lopez onde estão sendo realizados projetos de cunho social pelo IFSC.

\footnotetext{
O programa, que beneficiará centenas de moradores dos antigos quilombos do estado, vai promover ações em conjunto entre os dois Institutos Federais [IFSC e IFC] e amenizar a situação de vulnerabilidade social em que vivem os moradores dos territórios quilombolas (IFSC, 2010).
}

Essa atividade foi realizada no período de Julho a Setembro de 2011. A demanda inicial foi a criação de uma assinatura visual para comunidade e uma estampa que identificasse as atividades realizadas na comunidade.

A primeira parte do projeto se deu pela pesquisa de quem são os quilombolas no cenário Brasileiro atual, quem era a comunidade que estava sendo atendida e que projetos estavam sendo realizados pelo IFSC com a população da comunidade de Santa Cruz. A partir dos dados coletados e do conhecimento dos projetos que estavam sendo realizados foi notado que seria necessária uma representação gráfica da comunidade que possibilitasse sua identificação e proteção. Isso foi materializado por meio de uma assinatura visual e uma família de ícones complementares para identificar cada um dos projetos lá realizados.

Para tal foram realizadas pesquisas sobre aspectos visuais da cultura quilombola como cores, objetos e atividades a ele relacionadas. Também foi feito um estudo sobre o material gráfico já existente em relação aos quilombolas e cultura negra tanto no âmbito nacional como internacional.

Tendo como base o material coletado na pesquisa foram geradas alternativas e criadas a assinatura visual da comunidade, a família de ícones para os projetos e quatro diferentes tipos de estampas para camiseta. 


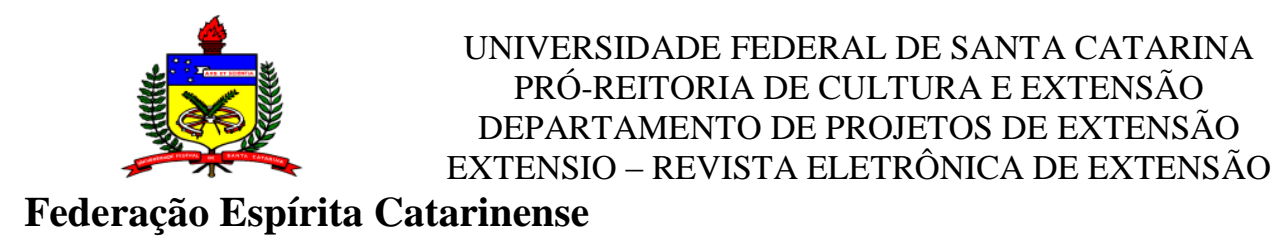

A atividade seguinte foi realizada no período de setembro a novembro de 2011. Nessa atividade a demanda inicial foi o redesign da assinatura visual da FEC (Federação Espírita Catarinense) e da assinatura visual das UREs (União regional espírita), sendo identificadas nessas demandas as reais necessidades a serem supridas pelo projeto. A FEC tem o objetivo de promover a unificação do espiritismo nos estados sulidos, possuindo um organograma próprio com cargos e funções definidas. Utiliza-se de Uniões Regionais para articular e unificar o espiritismo, através de áreas comuns adeptas às Uniões dentro de cada estado. Na primeira fase foi feita uma pesquisa que visou encontrar ações, objetos, fontes tipográficas e cores que fazem parte do mundo espírita.

Com a análise da pesquisa foi definido um desenho representativo a ser utilizado como base para o desenvolvimento da assinatura visual. Assim, foi desenvolvido um circulo, composto por pela representação de diferentes indivíduos de mãos dadas realizando uma atividade espiritual em conjunto. A partir desse símbolo foram geradas diferentes alternativas de tipos gráficos para a assinatura visual, realizando estudos de tipografia, cores e representações do símbolo para posterior definição da assinatura visual. Realizaram-se também testes de impressão e estudo de combinações dos elementos a comporem a assinatura visual da FEC e das UREs, bem como as aplicações de sua identidade em materiais institucionais, como papelaria e uniformes.

\section{ONG Travessia}

A ONG Travessia é uma instituição sem fins lucrativos que tem como objetivo principal transformar a realidade de vida das comunidades excluídas de São José, oferecendo a comunidade novas perspectivas de vida por meio da proporção de direitos fundamentais. $\mathrm{O}$ projeto foi realizado entre novembro de 2011 e fevereiro de 2012. Dessa forma, foi proposto a criação de folder e um redesign da assinatura visual, visto que esta assinatura apresentava problemas técnicos e semânticos. Para adequação da assinatura visual foi necessária uma análise, por meio da qual foi possível elencar e pontos onde poderia ser aperfeiçoada. Posteriormente a essa análise foi realizada uma pesquisa sobre as assinaturas visuais de ONGs similares para que se pudesse adequar a nova assinatura visual ao cenário gráfico atual do 


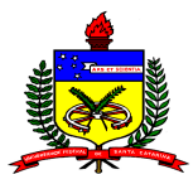

UNIVERSIDADE FEDERAL DE SANTA CATARINA

PRÓ-REITORIA DE CULTURA E EXTENSÃO

DEPARTAMENTO DE PROJETOS DE EXTENSÃO

EXTENSIO - REVISTA ELETRÔNICA DE EXTENSÃO

segmento, identificando um possível padrão de características e buscando meios também de diferenciar a ONG dentro de seu segmento.

No desenvolvimento folder, entre as necessidades estava disponibilizar as informações necessárias para divulgação dos projetos e informações sobre a ONG, levando em consideração um formato que gerasse menores custos para a instituição. A assinatura visual tinha o objetivo de ser lúdica e trazer elementos que remetessem a tecnologia. Para alcançar tal objetivo foi usado azul como cor predominante, caixas com bordas arredondadas para o texto e caixas com desenho de botões para os títulos.

\section{RESULTADOS E ANÁLISE}

O trabalho desenvolvido junto à Coofasul resultou no desenvolvimento de embalagens para impressão (Ilustração 04) dentro das normas da ANVISA. Com a finalização das embalagens os produtores da Coofasul poderão começar a competir com outros produtos que já estão no mercado e possuem grande apelo visual. O êxito da atividade realizada ainda não pode ser determinado por completo, pois as embalagens ainda não foram utilizadas comercialmente pela cooperativa. No entanto, a pesquisa de Teixeira (2011) apresenta resultados parciais positivos, entre os levantamentos feitos pelo autor cabe citar duas pesquisas de percepção aparente, realizadas junto aos produtores e potenciais consumidores da cooperativa Coofasul. Além disso, o projeto trouxe maior aproximação entre a academia e sociedade, na medida em que, por meio de demandas reais foi possível desenvolver, testar e propor soluções, principalmente de design. 


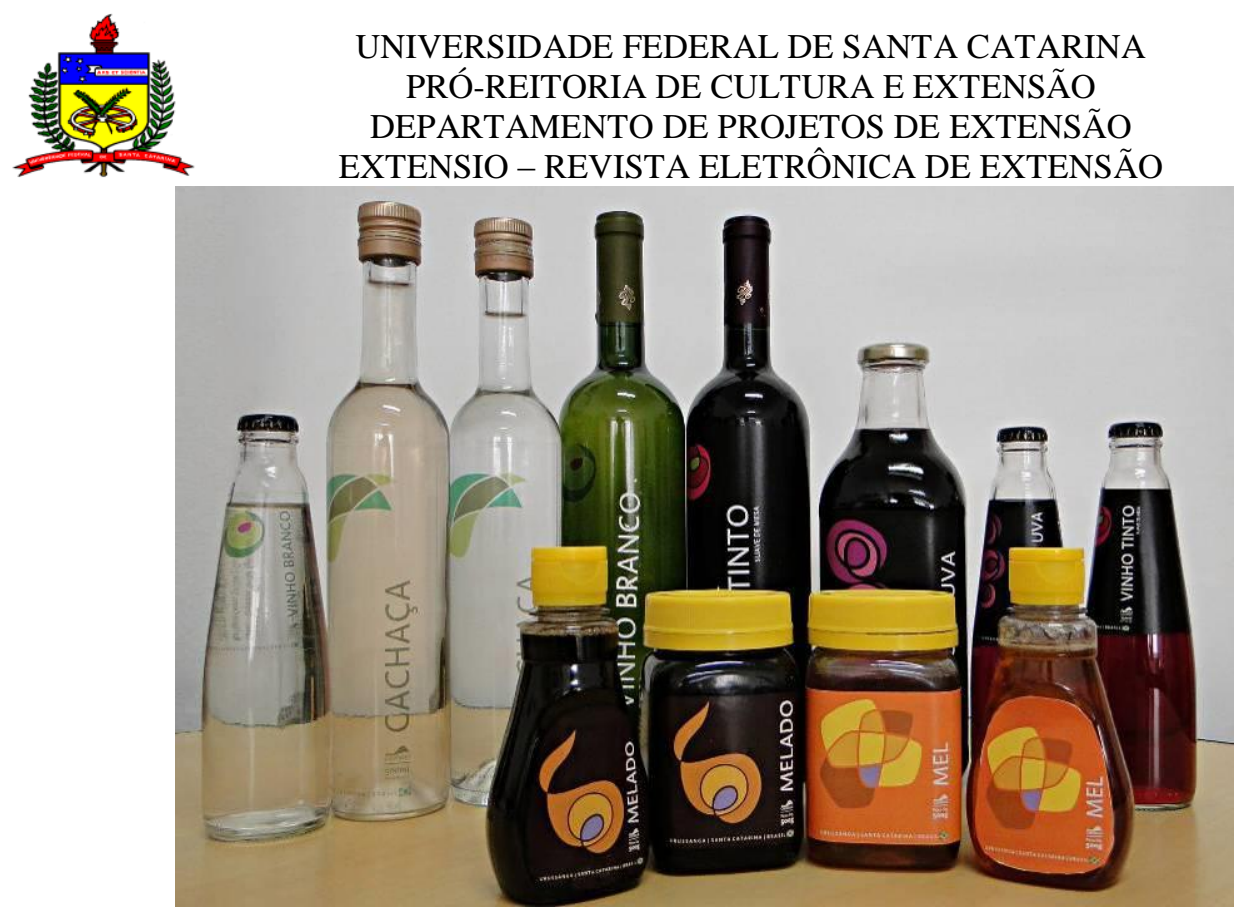

Ilustração 4 - Embalagens Coofasul.

Fonte: Teixeira, 2011.

$\mathrm{Na}$ atividade realizada junto ao IFSC para Comunidade de Remanescentes Quilombolas Santa Cruz cabe ressaltar como resultado a identidade visual da comunidade (Ilustração 5), a família de ícones para os projetos (Ilustração 6) e quatro diferentes tipos de estampas para camiseta (Ilustração 7). Todos com elementos que ilustram a cultura quilombola, sejam ícones da cultura ou as cores das peças. $\mathrm{O}$ material gerado nesse projeto está aguardando a aprovação do cliente para ser utilizado. Tendo como ponto de referencia os objetivos iniciais do projeto, as peças geradas obtiveram o êxito esperado uma vez que trazem elementos da cultura quilombola e possibilitam aos projetos realizados na comunidade ter mais visibilidade.

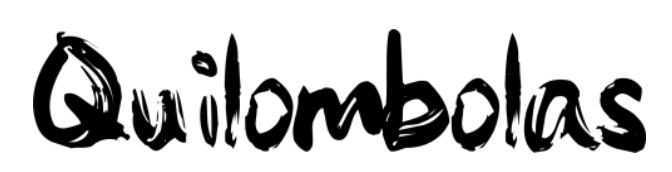

Ilustração 5 - Assinatura visual da Comunidade. Fonte: Acervo NGD, 2011. 


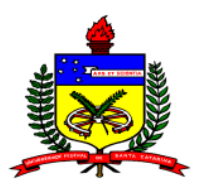

UNIVERSIDADE FEDERAL DE SANTA CATARINA PRÓ-REITORIA DE CULTURA E EXTENSÃO

DEPARTAMENTO DE PROJETOS DE EXTENSÃO

EXTENSIO - REVISTA ELETRÔNICA DE EXTENSÃO
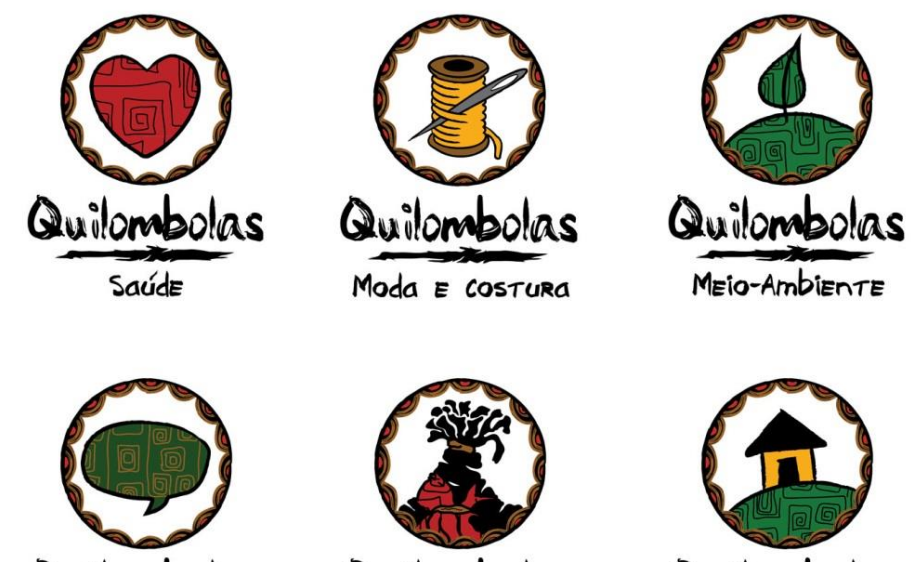

$\underset{\text { Quistória Oral }}{\text { Quilombolas }}$
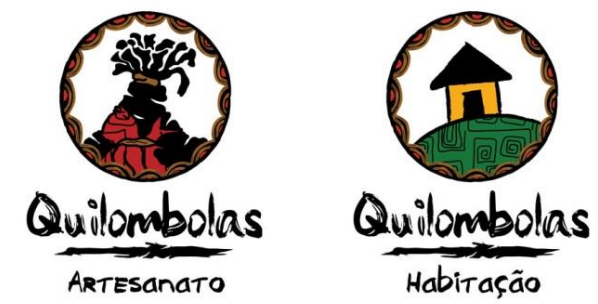

Ilustração 6 - Icones dos Projetos. Fonte: Acervo NGD, 2011.

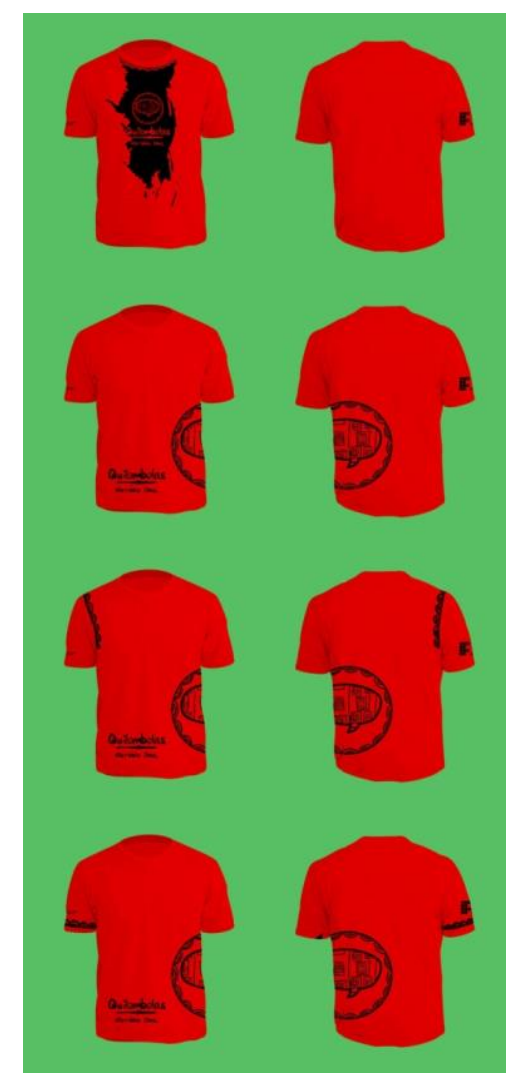

Ilustração 6 - Icones dos Projetos. Fonte: Acervo NGD, 2011.

$\mathrm{Na}$ atividade realizada para a FEC foram desenvolvidas diversas de soluções para a assinatura visual proposta a eles. Os resultados propõem a assinatura visual com o mesmo símbolo e fontes tipográficas diferentes (Ilustração 8), a assinatura visual proposta à URES foi 


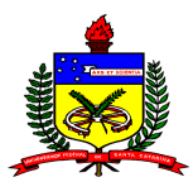

$$
\begin{aligned}
& \text { UNIVERSIDADE FEDERAL DE SANTA CATARINA } \\
& \text { PRÓ-REITORIA DE CULTURA E EXTENSÃO } \\
& \text { DEPARTAMENTO DE PROJETOS DE EXTENSÃO } \\
& \text { EXTENSIO - REVISTA ELETRÔNICA DE EXTENSÃO }
\end{aligned}
$$

finalizada e criada na sua versão para impressão e para uso digital (Ilustração 9). Também foram feitos testes de aplicação da assinatura visual em material de papelaria para instituição (Ilustração 10) e camisetas (Ilustração 11). Atualmente alguns itens gerados na atividade estão aguardando a aprovação do cliente a assinatura visual das UREs já foi aprovado. A atividade realizada obteve como resultado modelos de padronização de apresentação que proporcionaram maior coesão entre diferentes mídias, gerando uma imagem visual adequada a postura da instituição.

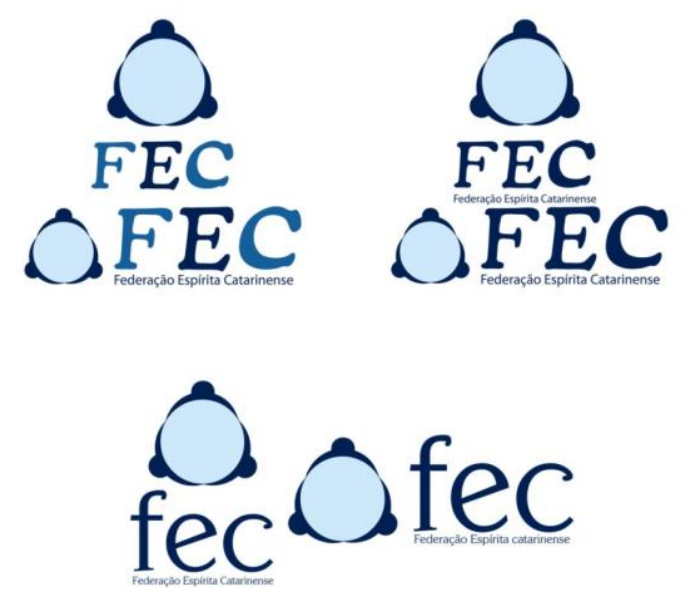

Ilustração 8 - Assinaturas visuais FEC eropostos ao cliente. Fonte: Acervo NGD, 2011.

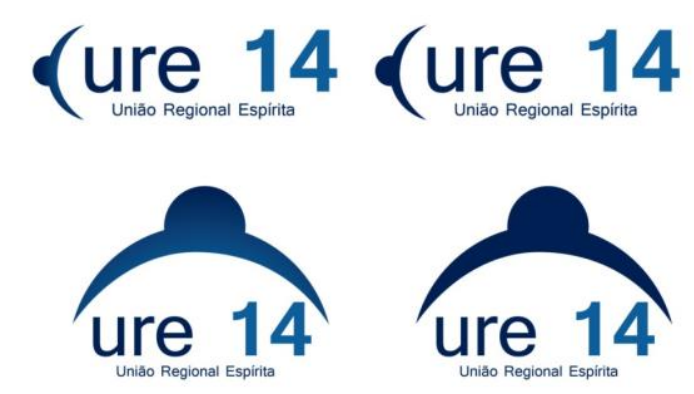

Ilustração 9 - Assinaturas visuais URE propostos ao cliente. Fonte: Acervo NGD, 2011. 
UNIVERSIDADE FEDERAL DE SANTA CATARINA

PRÓ-REITORIA DE CULTURA E EXTENSÃO

DEPARTAMENTO DE PROJETOS DE EXTENSÃO

EXTENSIO - REVISTA ELETRÔNICA DE EXTENSÃO

Cartão de Visitas

Frente

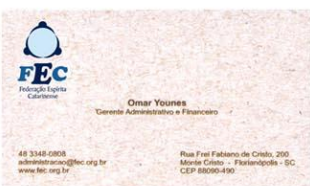

Papel Timbrado

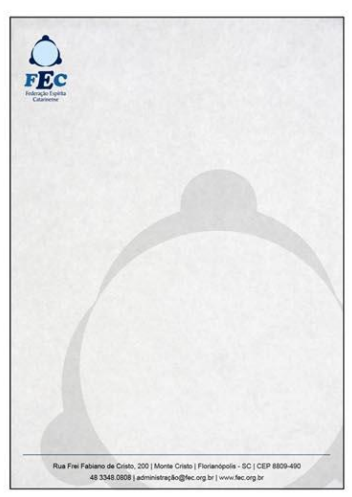

Envelope

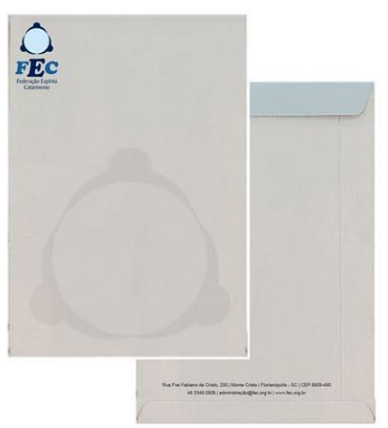

Verso

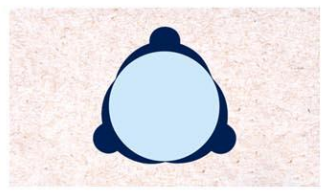

Pasta

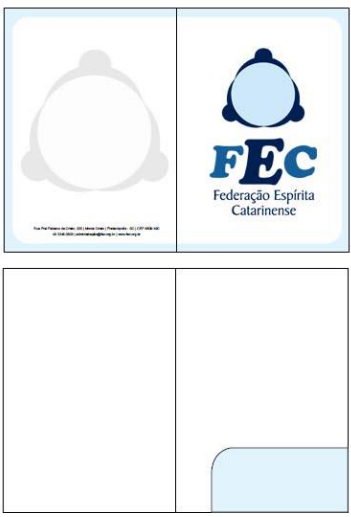

Envelope 2

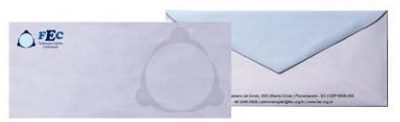

Ilustração 10 - Papelaria.

Fonte: Acervo NGD, 2011. 

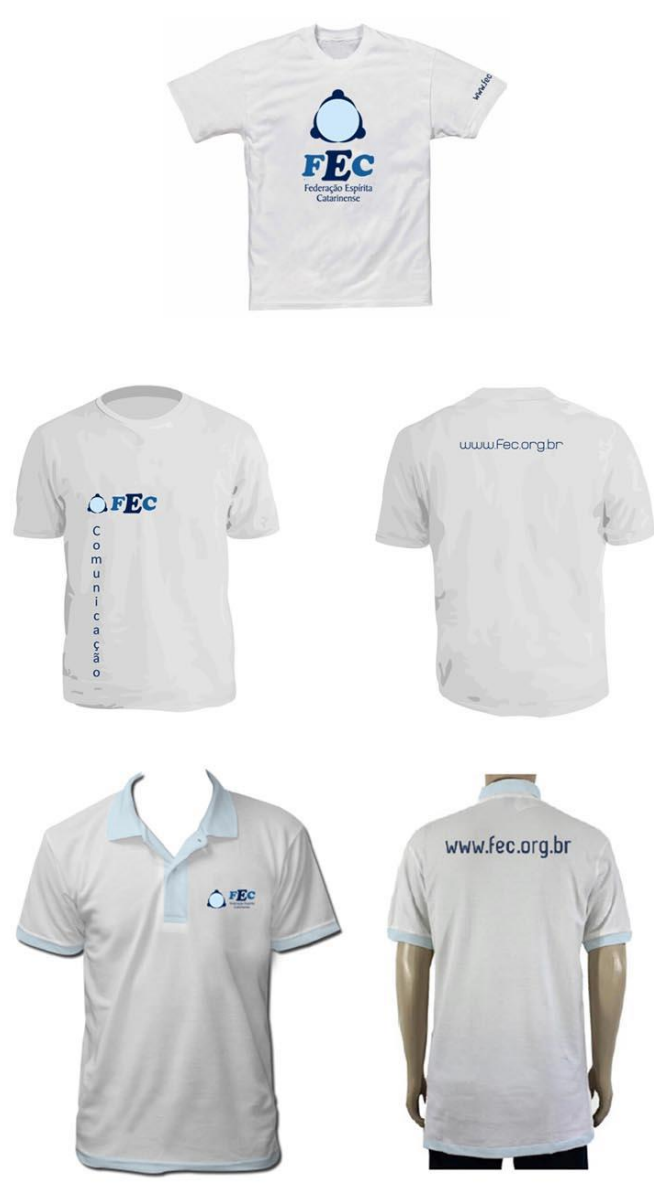

Ilustração 11 - Estampas Camisas FEC. Fonte: Acervo NGD, 2011.

A última atividade, realizada junto a ONG Travessia trouxe como resultados a assinatura visual (Ilustração 12) e um folder (Ilustração 13), a assinatura visual traz como símbolo o pórtico de São José e uma fonte tipográfica estilizada. O folder traz todas as informações necessárias sobre os serviços prestados pela ONG Travessia, além de um breve histórico e as informações para contato. As peças criadas nessa atividade possibilitaram uma nova linguagem visual à ONG travessia, a nova assinatura visual redesenhada possibilita uma melhor aplicação nos matérias gráficos da ONG e o folder criado permitirá a ONG Travessia ter mais um veículo para divulgar seus projetos. Com a aplicação da assinatura visual

reformulada e a padronização da linguagem e apresentação visual da ONG em diferentes mídias e veiculações, foi possível notar maior percepção de valor pelo próprio responsável 


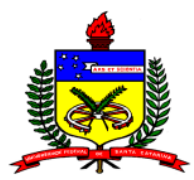

\section{UNIVERSIDADE FEDERAL DE SANTA CATARINA \\ PRÓ-REITORIA DE CULTURA E EXTENSÃO}

DEPARTAMENTO DE PROJETOS DE EXTENSÃO

EXTENSIO - REVISTA ELETRÔNICA DE EXTENSÃO

pela ONG, segundo ele isso contribui para valorização de seu trabalho e possibilita maior visibilidade por meio da disseminação de sua identidade pela região.

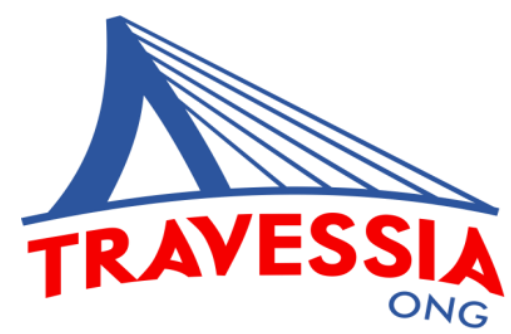

Ilustração 12 - Assinatura visual ONG Travessia. Fonte: Acervo NGD, 2011.
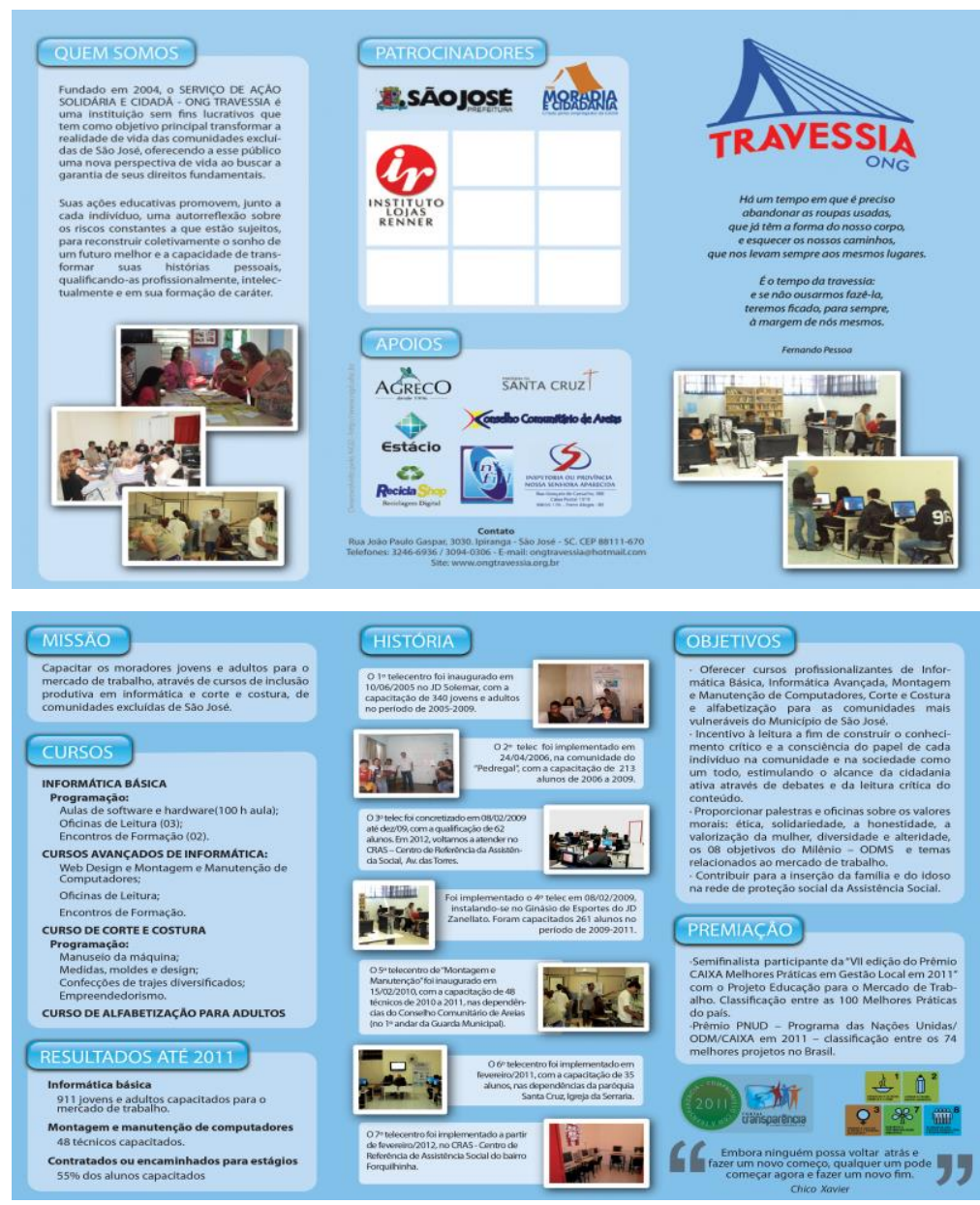

Ilustração 13 - Proposta Folder para ONG Travessia. Fonte: Acervo NGD, 2011. 


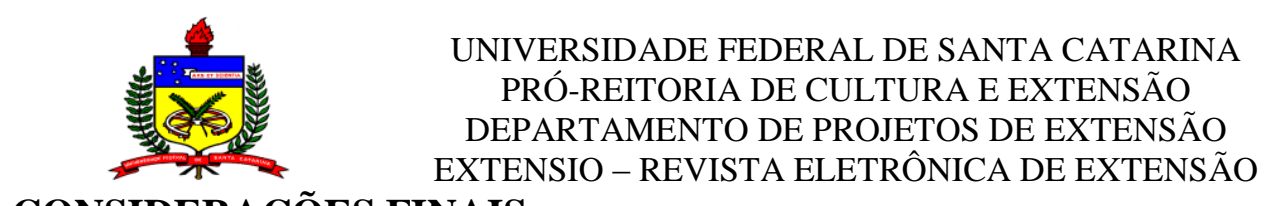

\section{CONSIDERAÇÕES FINAIS}

PRO-REITORIA DE CULTURA E EXTENSÃO

DEPARTAMENTO DE PROJETOS DE EXTENSÃO

Nas atividades realizadas no projeto "Valorização e proteção da produção de pequenos produtores: cooperativas em Santa Catarina" a utilização da metodologia de design GODP foi fundamental para o cumprimento da demanda de produção gráfica.

As atividades desenvolvidas buscaram valorização das organizações por meio do material criado para ele, tanto através da criação de uma assinatura visual como de um folder informativo. Utilizando como metodologia o GODP, ferramenta importante no processo de desenvolvimento de projeto, o design pode contribuir além de uma solução estética. Com a aplicação do GODP nas atividades de extensão foi possível encontrar uma melhor solução para as demandas, expandir o universo de atuação do projeto em prol do desenvolvimento e crescimento do grupo ou entidade. Entre os benefícios gerados pelo trabalho, vale mencionar:

A) Valorização dos grupos produtivos e comunidades envolvidas. Tal valorização foi possível por meio da melhor identificação, proteção e criação de veículos de informação padronizados conforme a linguagem e identidade visual desenvolvida, aplicando-se a camisetas, folders, websites, material de papelaria, entre outros;

B) Aumento do alcance e visibilidade das entidades envolvidas, com desenvolvimento de estratégias de design que levassem as informações aos públicos visados;

C) Melhorias na percepção do público externo (caso Coofasul) e interno também quanto ao trabalho realizado nas outras entidades;

D) Disseminação e valorização da atividade do design, ao proporcionar benefícios à grupos e comunidades que não tinham familiaridade com esta área do conhecimento até então, podendo estas assim absorver suas potencialidades;

E) Desenvolvimento de parcerias com as entidades, que geram futuros projetos e possibilidades de trabalhos, podendo contribuir para futuras pesquisas e atividades de extensão.

\section{REFERÊNCIAS}

ANDRADE, Erica Ribeiro de. Interferências do design na dimensão econômica da sustentabilidade. 2012. 209 f. Dissertação (Mestrado) - UFSC, Florianópolis, 2012.

AMBROSE, G., HARRIS, P. Design Thinking. Ava Books, Switzerland, 2010. 
BROWN, T. Change by design. Harper Collins Publishers, New York, 2009.

BROWN, T., WYATT, J. Design Thinking for Social Innovation. Stanford Social Innovation Review, Winter 2010.

DMI. Design Management Institute. Design Thinking: integrating innovation, customer experience, and brand value. Edited by Thomas Lockwood, USA, 2010.

IF-SC. IF-SC vai elaborar programa de formação profissional para remanescentes quilombolas Disponível em: http://www.ifsc.edu.br/9-noticias/1119-0508-if-sc-vai-elaborarprograma-de-formacao-profissional-para-remanescentes-quilombolas. Acesso em: 05 ago. 2010.

MERINO, Giselle Schmidt Alves Díaz. A contribuição da gestão de design em grupos produtivos de pequeno porte no setor da maricultura: o caso AMPROSUL. 2010. $206 \mathrm{f}$. Dissertação (Mestrado) - UFSC, Florianópolis, 2010.

MERINO, Giselle; GONTIJO, Leila Amaral; MERINO, Eugenio. O percurso do design: no ensino e na prática. In: TEIXEIRA, Carlos et al. Cadernos de Estudos Avançados em Design: Método. Barbacena: Eduemg, 2011.p. 67-85.

TEIXEIRA, Julio Monteiro. Identificação e proteção: o design valorizando grupos produtivos de pequeno porte. 2011. 177 f. Dissertação (Mestrado) - UFSC, Florianópolis, 2011. 